\title{
Vibration Signal Analysis of Water Seal Blasting Based on Wavelet Threshold Denoising and HHT Transformation
}

\author{
Jiang-chao Liu and Wen-xue Gao iD \\ College of Architecture and Civil Engineering, Beijing University of Technology, Beijing 100124, China \\ Correspondence should be addressed to Wen-xue Gao; wxgao@bjut.edu.cn
}

Received 14 November 2019; Revised 7 January 2020; Accepted 17 January 2020; Published 9 March 2020

Academic Editor: Jiang Jin

Copyright () 2020 Jiang-chao Liu and Wen-xue Gao. This is an open access article distributed under the Creative Commons Attribution License, which permits unrestricted use, distribution, and reproduction in any medium, provided the original work is properly cited.

\begin{abstract}
The blasting vibration signal obtained from tunnel construction monitoring is affected by the external environment, which contains a lot of noise that causes distortion during signal processing. To analyse the blasting vibration signal and determine the appropriate water seal blasting charge structure for construction, combined with wavelet threshold denoising method and HHT transformation, the blasting vibration signals of the four charge structures of conventional charge, water interval charge at both ends, water interval charge at the orifice, and water interval charge at the hole bottom are denoised and HHT is analysed. The results show that the wavelet threshold method can effectively eliminate high-frequency noise in the blasting vibration signals and retain information carried by the vibration signal itself. The frequency and energy of the blasting vibration signals of the water interval charge at both ends are densely distributed in the range of $0 \mathrm{~s}$ to $0.9 \mathrm{~s}$ and below $100 \mathrm{~Hz}$. The frequency and energy of the blasting signals of the other three charging structures are reduced within the same range, sparse areas appear, and the instantaneous total energy is smaller than that with a water interval charge at both ends, which shows that the water interval charge at both ends can effectively apply explosive energy to the surrounding rock and reduce energy loss in the explosive. The blasting vibration signal energy of the water interval charge at both ends is mainly concentrated in components IMF2 to IMF5, and the corresponding frequencies are concentrated at $6 \mathrm{~Hz}$ to $11 \mathrm{~Hz}$ and $20 \mathrm{~Hz}$ to $70 \mathrm{~Hz}$, while the blasting vibration signal energy of other three charge structures is mainly distributed in components IMF2 to IMF4, corresponding frequencies are concentrated within $20 \mathrm{~Hz}$ to $70 \mathrm{~Hz}$, and the distribution at low frequencies is not obvious. Therefore, when using the water interval charge at both ends, it is necessary to increase the main vibration frequency of the original vibration signals by reducing the single section charge and using frequency shift technology to avoid the natural frequency of the structure and reduce resonance-induced damage.
\end{abstract}

\section{Introduction}

In the tunnel blasting process, in addition to crushing the rock, the explosive energy propagates within the surrounding rock to form a vibration signal in the form of stress waves. Blasting vibration signals not only reflect the dynamic mechanical characteristics of the surrounding rock but also contain much useful feature information [1-3]. Therefore, the monitoring and analysis of blasting vibration velocity can provide a reference for the safe construction of tunnels, which is of great importance [4-6].

There are many ways to analyse vibration signals: Liu et al. used MATLAB ${ }^{\mathrm{TM}}$ combined with wavelet analysis to analyse the energy of blasting vibration signals monitored in practice. According to the frequency domain energy of the main vibration frequency of the blasting vibration signals and the frequency domain energy of the controlled structure self-vibration frequency, a new method of blasting hazard evaluation was proposed [7]. Cao et al. used the HHT method to analyse the measured blasting vibration signals from the perspective of their time-frequency and energy distribution characteristics and then assessed the safety of a slope and surrounding buildings [8]. Wang et al. used the HHT method to obtain the Hilbert spectrum, marginal spectrum, and instantaneous energy diagram of blasting vibration signals and studied the effect of blasting vibration on nearby tunnels [9]. Ning et al. use the wavelet packet analysis method to decompose vibration signals collected in 
the field and assess the attenuation of vibration waves after stope blasting [10]. Li et al. used multifractal analysis to analyse the singular spectrum of vibration signals and then used a multifractal spectrum derived by use of the wavelet transform [11]. Among them, the HHT method is a relatively new time-frequency analysis method, which has the advantages of self-adaptability, no need to fix an a priori basis, and suitability for the analysis of nonstationary signals.

The blasting vibration signals monitored in the field often contain noise, which affects the effectiveness of signal analysis. Therefore, people use various means to denoise such signals. The common denoising methods of blasting vibration include wavelet technology (wavelet threshold denoising, modulus maximum wavelet denoising, wavelet packet threshold denoising, translation invariant wavelet denoising, etc.), empirical mode decomposition technology (EMD denoising, EEMD denoising, etc.), and combinations of the two methods (EMD-wavelet threshold denoising). Yang et al. used EMD-FSWT and EEMD-SPWV methods to analyse blasting vibration signals and discussed the noise reduction effect of EMD-FSWT and the multifractal characteristics of blasting vibration signals in the scale-free zone $[12,13]$. Shao adopts a low-pass denoising method based on CEEMD (Complementary Ensemble Empirical Mode Decomposition), which can not only eliminate the irregular noise in the tunnel blasting vibration signals but also preserve the authenticity and integrity of the signals [14]. To overcome the fact that EEMD denoising cannot deal with IMFs, Wei et al. combine the " $3 \sigma$ " rule and Singular Value Decomposition (SVD) to improve EEMD denoising [15]. According to the characteristics of decomposition and reconstruction of the EMD method and the flexibility and debuggability of wavelet threshold methods, Rao et al. proposed the EMD-wavelet threshold denoising method [16]. Among them, wavelet threshold denoising is widely used because of its fast calculation and reasonable denoising capabilities.

For environmental protection, water seal blasting has attracted much attention because of its good blasting effect and reducing blasting dust emissions; however, there are few reports on the differences in vibration signals between the charge structure of water-sealed blasting and conventional blasting. Therefore, we take the Wenquan Tunnel in Beijing Yanchong Expressway as the engineering background and combine the wavelet threshold denoising and HHT methods to compare and analyse the measured vibration signals of water seal blasting and conventional blasting signals. According to the analytical results, the appropriate water seal blasting charge structure is selected for tunnel construction.

\section{The Principle of Wavelet Threshold Denoising and HHT}

2.1. Wavelet Threshold Denoising Principle. Donoho and Johnstone proposed the wavelet threshold shrinkage denoising method in 1994: therein, they mentioned the concept of wavelet threshold denoising [17]. Wavelet threshold denoising is a method that maps the signals to the wavelet domain. According to the different properties and mechanisms of the wavelet coefficients of noise and noise on different scales, the wavelet coefficients of noisy signals are processed. The blasting vibration signals are decomposed by wavelet transformation to generate low-frequency wavelet coefficients and high-frequency wavelet coefficients. The real signal is a low-frequency signal and the noise is a highfrequency signal. When increasing the number of decomposition layers, the correlation coefficients between lowfrequency wavelet coefficients and real signals will change from low to high and then to low. When the correlation coefficient reaches its highest value, it can be set as a threshold value, the wavelet coefficients containing the noise are filtered and inverted, and then the denoised signals can be obtained (Figure 1). Wavelet threshold denoising is one of the most widely used methods of wavelet denoising because of its advantages such as approximate optimal estimation of the original signal, fast computing speed, and wide adaptability [16, 18-20]. In addition, wavelet threshold denoising can almost completely suppress the noise, and the peak points reflecting the original signal characteristics can be well preserved.

2.2. Selection of Threshold. In the process of threshold selection, choosing the appropriate threshold has an important influence on the effect of noise reduction. If the threshold value is too small, the signal noise reduction is not complete; if the threshold value is too large, the useful signal will be deleted and the accuracy will be affected. The main methods for selecting the threshold are discussed in the following.

\subsubsection{General Threshold Method (Sqtwolog). General} threshold method is the conclusion and the best threshold for the joint distribution of multidimensional independent normal variables when the dimensionality tends to infinity and the minimum maximum estimation limit. When this method is used, the same threshold value is applied to wavelet decomposition to get all levels of wavelet coefficients, and the estimation results are relatively smooth. The formula for calculating the threshold of the general threshold method is as follows:

$$
T=\sigma \sqrt{2 \ln N}
$$

where $N$ is the sampling length of the signal and $\sigma$ is the variance of the noise signal. $\sigma=\operatorname{median}\left(W^{\mathrm{HH}}\right) / 0.6475, W^{\mathrm{HH}}$ are the orthogonal wavelet coefficients of noise in the highfrequency subband, and median denotes taking the median average.

\subsubsection{Stein Unbiased Risk Threshold Method (Rigrsure).} Stein unbiased risk threshold method is an adaptive threshold selection based on the principle of Stein unbiased likelihood estimation. Given a threshold value to its likelihood estimation, the selected threshold can be obtained by minimizing the nonlikelihood threshold value. Assuming $P=\left[p_{1}, p_{2}, \ldots, p_{n}\right]$ and $p_{1}<p_{2}<\cdots<p_{n}$, the elements contained in $P$ are the squares of the wavelet coefficients 


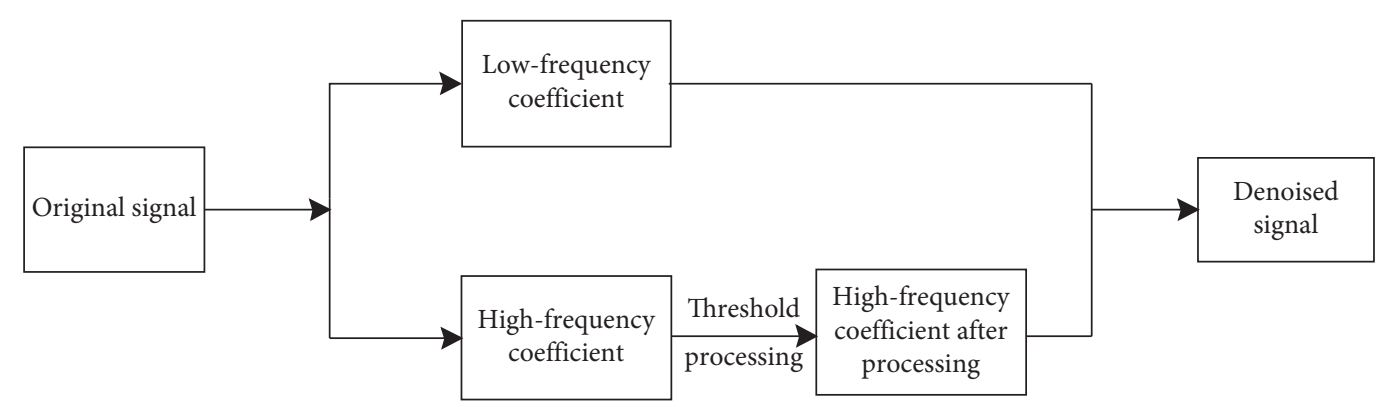

Figure 1: Wavelet threshold denoising process.

arranged in ascending order. If $R$ is defined as a risk trace, the element $r_{i}$ therein is

$$
r_{i}=\frac{\left[N-2 i-(n-i) p_{i}+\sum_{k=1}^{i} p_{k}\right]}{N}, \quad i=1,2, \ldots, N .
$$

When the minimum value $r_{\min }$ of the element in $R$ is selected as the risk value, the threshold calculation formula is as follows:

$$
T=\sigma \sqrt{P_{\min }}
$$

2.2.3. Heuristic Threshold Method (Heursure). The heuristic threshold method selects the optimal prediction variable threshold. In practical processing, when the signal-to-noise ratio is small, the error of the Stein unbiased risk threshold method in calculating the threshold is not conducive to accurate signal denoising analysis. The heuristic threshold method combines the advantages of the general threshold and Stein unbiased risk threshold. When the signal-to-noise ratio is low, the general threshold method is used to calculate the threshold. When the signal-to-noise ratio is high, the Stein unbiased risk threshold method is used to calculate the threshold.

2.2.4. Minimax Threshold Method (Minimax). The minimax threshold method uses the minimax principle to generate the threshold value and uses the minimum mean square error as the objective function to generate an extreme value. This threshold estimator minimizes the maximum mean square error in a given function. The principle of the minimax threshold method is to minimise the maximum risk of prediction. The calculation method of threshold is as follows:

$$
T= \begin{cases}\sigma\left(0.3963+0.1829\left(\frac{\ln N}{\ln 2}\right)\right), & N>32, \\ 0, & N \leq 32 .\end{cases}
$$

Because the threshold selection rules of rigrsure and minimax are conservative, only a part of the coefficients are set to zero. Therefore, these two thresholds are very useful to extract small and weak signals when a small part of the highfrequency information is in the noise range. However, the selection rules of heursure threshold and sqtwolog threshold are more effective in removing noise, but the high-frequency part of useful signal may be removed as noise signal. The above four thresholds are used for noise reduction of noisy signals, and the standard deviation is calculated [18]. The calculation results are shown in Table 1. It can be seen from Table 1 that using the sqtwolog threshold noise reduction can get better results.

2.3. Selection of Threshold Function. In addition to the aforementioned threshold selection, the threshold function is an important factor affecting wavelet denoising; at present, there are two kinds of commonly used threshold functions: hard threshold functions and soft threshold functions. The two functions are expressed as follows:

(1) Hard threshold function

$$
\hat{d}_{j, k}= \begin{cases}d_{j, k}, & \left|d_{j, k}\right| \geq T \\ 0, & \left|d_{j, k}\right|<T\end{cases}
$$

(2) Soft threshold function

$$
\hat{d}_{j, k}= \begin{cases}\operatorname{sgn}\left(d_{j, k}\right)\left(\left|d_{j, k}\right|-T\right), & \left|d_{j, k}\right| \geq T, \\ 0, & \left|d_{j, k}\right|<T,\end{cases}
$$

where $d_{j, k}$ are the original wavelet coefficients; $\hat{d}_{j, k}$ are the estimated wavelet coefficients after calculating the threshold function; $T$ is the threshold. Figure 2 shows the difference between the two threshold functions.

By comparing mean square error of the two functions, the hard threshold function is better than the soft threshold function; however, due to the influence of discontinuity in the function, the estimated signal from the hard threshold function will produce oscillations, while the wavelet coefficients from the soft threshold function have better overall continuity, so that the estimated signal will not be accompanied by additional oscillations, and the signal, after noise reduction, will be smoother [18]. Therefore, soft threshold function is selected for analysis.

2.4. Basic Principles of HHT. Huang et al. proposed the HHT method at the end of the last century [21]. The principle thereof is to change the unstable random signal into a stationary signal. First, empirical mode analysis (EMD) is 
TABLE 1: Standard deviation of noisy signal and different threshold after noise reduction [18].

\begin{tabular}{lcccc}
\hline Noisy signal & Sqtwolog & Rigrsure & Heursure & Minimax \\
\hline 0.0504 & 0.0138 & 0.0223 & 0.0168 & 0.0165 \\
\hline
\end{tabular}

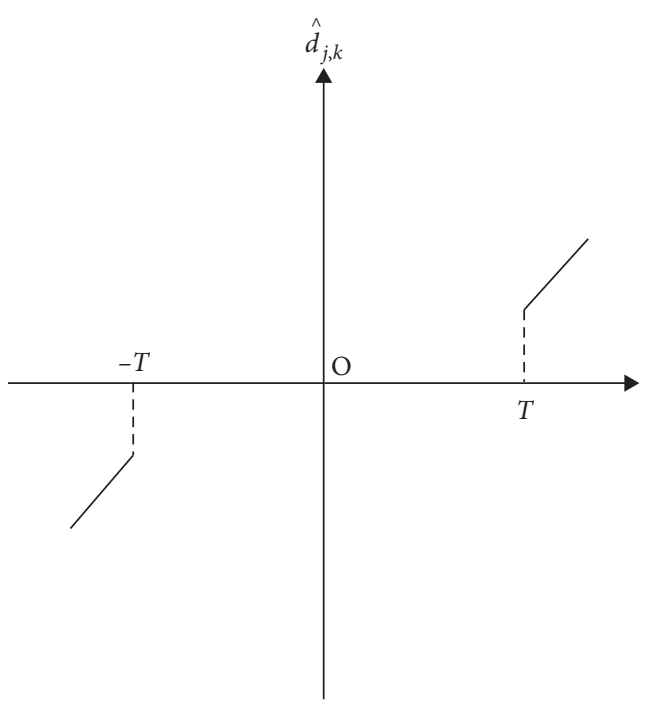

(a)

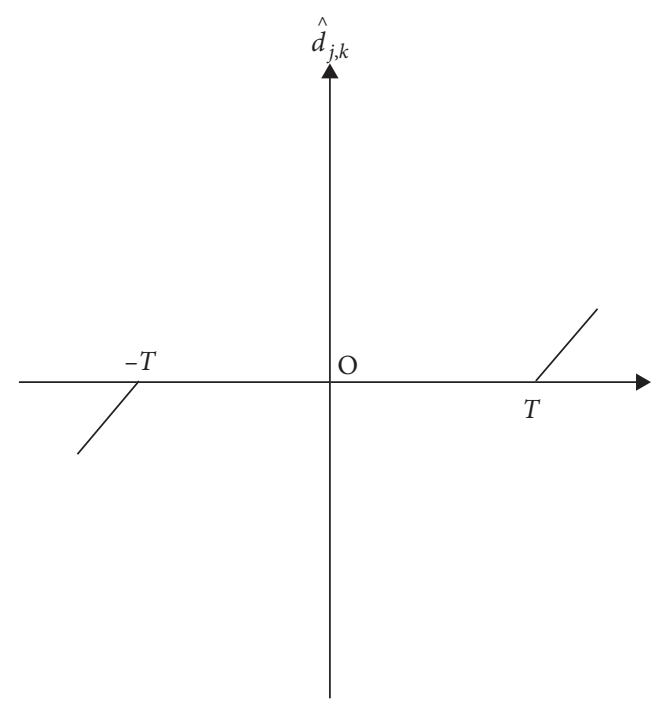

(b)

Figure 2: Threshold function. (a) Hard threshold function. (b) Soft threshold function.

used to process the blasting vibration signals, and then several groups of intrinsic mode functions (IMFs) representing the time-scale of the blasting vibration signals can be obtained. The physical meaning of IMFs is the amplitude or frequency modulation signals of each single component. Finally, the decomposed groups of IMFs are transformed by Hilbert transform. In other words, the time, frequency, and energy distribution of the blasting vibration signals are finally obtained.

2.5. Empirical Modal Analysis and Hilbert Transform. To study transient and nonstationary phenomena, the frequency must be a function related to time; however, no consensus as to the definition of instantaneous frequency has been reached. To obtain an effective and representative instantaneous frequency, Huang and others propose the necessary conditions for satisfying a meaningful instantaneous frequency (IF) in terms of physical characteristics: functions must be symmetric with respect to local zero mean and have the same extremum and zero-crossing points. Then the intrinsic mode function (IMF) is defined as the function satisfying the following two conditions that, when using EMD to analyse vibration signals, must be satisfied:

(1) In the whole data sequence, the number of extreme points and the number of zero-crossing points must be equal or differ at most by one.

(2) At any point on the signal, the mean value of the envelope determined by the local maximum point and the envelope determined by the local minimum point are both zero. That is, the signal is locally symmetric with respect to the time axis.

The Hilbert transform is applied to multiple IMF signals obtained by the EMD method. The instantaneous spectrum of each IMF component can be obtained. The Hilbert spectrum can be obtained by synthesising the instantaneous spectrum of all IMF components. The Hilbert transform is a type of linear transformation, which emphasises the local properties of the signal. The instantaneous frequency obtained by use of the Hilbert transform is the best definition: it avoids many spurious high- and low-frequency components produced by the Fourier transform.

\section{Field Test of Water-Sealed Blasting}

3.1. Engineering Context. The Beijing Yanchong Expressway (Beijing section) project is a key supporting project jointly organised by Beijing and Zhangjiakou City for the 2022 Winter Olympics. In this test, the Wenquan Tunnel on the Yanchong Expressway (Beijing section) is taken as the engineering background against which to conduct conventional blasting and water seal blasting tests with different charging structures. The excavation of the hot spring tunnel involves drilling through rock (both hard rock and associated secondary rock). The lithology of the tunnel section is weak, the joint fissures are developed, the rock is broken, and the stability thereof is poor. According to the comprehensive consideration of tunnel section size, surrounding rock stability and construction continuity, the millisecond delay blasting method is adopted for upper and lower steps. The 
blast-hole on the excavation section of the upper bench is detonated according to the partition arrangement and sequence of the cutting hole, the auxiliary hole, and the peripheral hole and gradually expands to complete a blasting excavation. Horizontal hole slotting blasting is adopted in the lower bench to reduce damage to the lining and the surface of the upper bench.

\subsection{Test Method}

3.2.1. Tunnel Blasting Design. This test is based on the upper bench blasting, and its cyclical footage is controlled to $3 \mathrm{~m}$. The length of auxiliary hole and peripheral hole is $3.3 \mathrm{~m}$, the length of the cut hole is $3.5 \mathrm{~m}$, and the diameter of the borehole is $42 \mathrm{~mm}$. The arrangement of the blast-hole and initiation sequence are shown in Figure 3; relevant parameters are listed in Table 2.

3.2.2. Charge Structure. To highlight the characteristics of water-sealed blasting, water-sealed blasting is compared with conventional blasting. In this test, four charging structures are used: (a) conventional charge structure, (b) water interval charge at both ends, (c) water interval charge at the orifice, and (d) water interval charge at the hole bottom. The charge structure is shown in Figure 4.

To reduce the influence of external conditions, the quantity of charge in the same type of blast-hole is the same in the four charge structures. The stemming length of the blast-hole is $0.9 \mathrm{~m}$. The water length is $0.6 \mathrm{~m}$ (the water length of two sections in the water interval charge at both ends is $0.3 \mathrm{~m}$ ), and the air-gap length is $0.6 \mathrm{~m}$.

3.2.3. Blasting Vibration Monitoring. To monitor the vibration signals of blasting effectively, a series of tests was conducted for conventional blasting and water-sealed blasting with different charging structures. According to the actual situation of the site and under the premise of ensuring safety, vibration monitoring point is arranged $50 \mathrm{~m}$ from the centreline of the upper step of the tunnel to the tunnel face (Figure 5).

3.2.4. Monitoring Instrument. TC- 4850 blasting signal recorder is selected as the monitoring instrument, as shown in Figure 6. The recorder is equipped with embedded computer module and LCD, which can directly debug parameters on the instrument and preview the information of vibration speed peak value, frequency, and waveform immediately after sampling. The range of the explosion vibration recorder is set to $0.001 \mathrm{~cm} / \mathrm{s} \sim 35.4 \mathrm{~cm} / \mathrm{s}$, the sampling frequency is $8000 \mathrm{~Hz}$, the sampling time is $5 \mathrm{~s}$, and the triggering level is $0.2 \mathrm{~V}$. The instrument has $128 \mathrm{M}$ storage space, which can continuously trigger the recording and storage.

\section{Signal Denoising and Analysis}

4.1. Signal Noise Reduction Processing. According to the "National Standard of the People's Republic of China
Blasting Safety Regulation (GB6722-2014)" [22], the vibration speed can be used as the standard for blasting vibration damage and protection. By comparing and analysing the in situ monitoring data, the results show that the vertical vibration velocity $Z$ (vertical pavement) is greater than the lateral $X$ (parallel tunnel face) and the longitudinal $Y$ (vertical tunnel face) velocities. Therefore, the vertical vibration velocity is selected as the criterion for comparative analysis.

In the process of field blasting, the blasting vibration signals contain a large amount of blasting information. Time-frequency analysis is an important object of blasting research; however, the environment is often complicated and subject to the effects of interference from reflection and refraction of blasting signals in the propagating medium, external magnetic fields, and so forth, which cause the monitored signals to contain noise that affects the accuracy of signal analysis. It is necessary to denoise the signal to improve the accuracy of signal analysis. In this paper, the general threshold (sqtwolog) combined with wavelet threshold denoising method of soft threshold function is used to process blasting vibration signals of four charge structures $[23,24]$. The effect of noise reduction is shown in Figure 7.

Figure 7 shows that there are few differences between the original signals and the denoised signals after the blasting signals are denoised by the wavelet threshold method. It is shown that the wavelet threshold method can effectively preserve the information carried by the blasting signals while denoising the signals. Therefore, we take the vibration signals after noise reduction as the analysis object and compare the vibration signals generated after the four charge structures are detonated. It is found that the vibration signals can reflect the time difference between the different stages of explosive detonation, and the peak vibration velocity is concentrated between 0 and $0.15 \mathrm{~s}$. At this time, the corresponding blast-hole is the cutting hole. This is because there is only one free surface in the cut hole blasting, which is most affected by the surrounding rock, and the energy transferred into the surrounding rock after the explosion is greater. In addition, to provide a good free surface for auxiliary hole blasting, the amount of charge in the cut hole is larger than that in other blast-holes, so the peak vibration velocity in the vibration signal often occurs in the cut hole blasting stage.

4.2. Comparative Analysis of Peak Vibration Velocity. We compare the peak vibration speeds after denoising the blasting vibration signals of the four charge structures (Table 3).

As can be seen from Table 3 , the peak vibration velocities of four charge structures after explosion are different for a given amount of charge. The peak vibration velocities (in descending order) are as follows: the peak vibration velocity of a water interval charge at both ends is $4.14 \mathrm{~cm} \mathrm{~s}^{-1}$, the peak vibration velocity of a water interval charge at the orifice is $3.71 \mathrm{~cm} \mathrm{~s}^{-1}$, the peak velocity of conventional charge structure is $3.52 \mathrm{~cm} \mathrm{~s}^{-1} \mathrm{~cm} / \mathrm{s}$, and the peak vibration velocity 

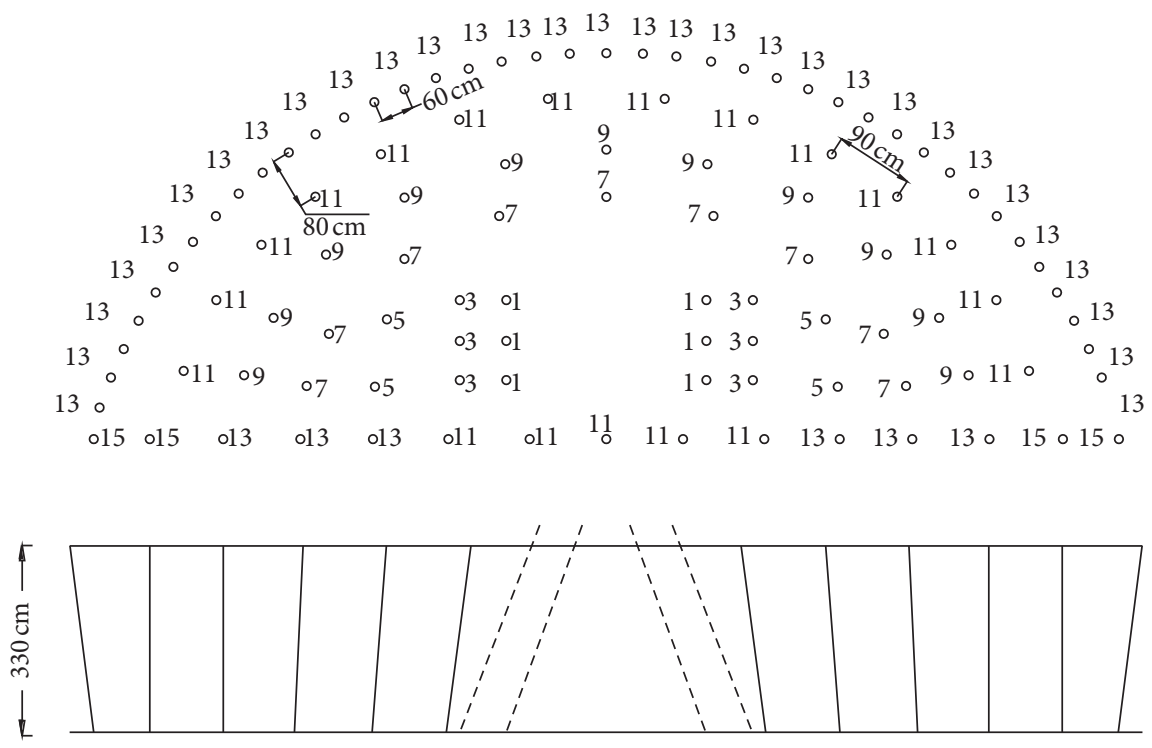

Figure 3: Blast-hole arrangement and detonation sequence.

TABLE 2: Main blasting parameters of the upper bench.

\begin{tabular}{|c|c|c|c|c|c|}
\hline Blast-hole type & Blast-hole diameter (mm) & Detonator section & Delay time (ms) & Blast-hole depth $(\mathrm{m})$ & Single hole charge $(\mathrm{kg})$ \\
\hline Cutting hole & 42 & $\begin{array}{l}1 \\
3 \\
\end{array}$ & $\begin{array}{c}<13 \\
50 \pm 10\end{array}$ & 3.5 & 2.7 \\
\hline Auxiliary hole & 42 & $\begin{array}{c}5 \\
7 \\
9 \\
11 \\
\end{array}$ & $\begin{array}{l}110 \pm 15 \\
200 \pm 20 \\
310 \pm 20 \\
460 \pm 20\end{array}$ & 3.3 & 1.8 \\
\hline Peripheral hole & 42 & $\begin{array}{l}11 \\
13 \\
15\end{array}$ & $\begin{array}{l}460 \pm 20 \\
650 \pm 25 \\
880 \pm 60\end{array}$ & 3.3 & 1.2 \\
\hline
\end{tabular}

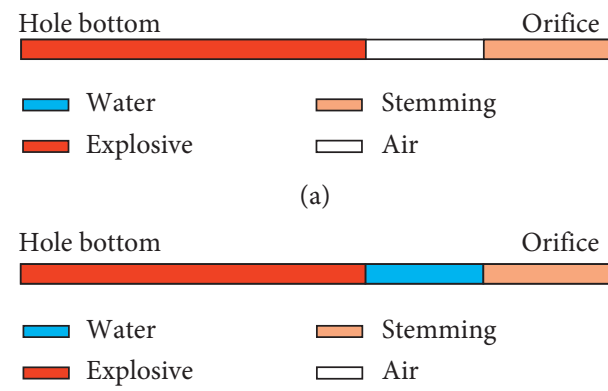

(c)

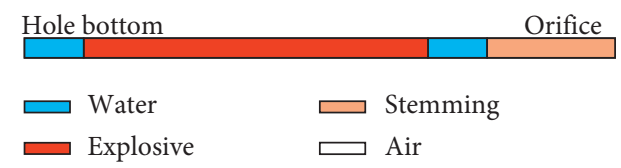

(b)

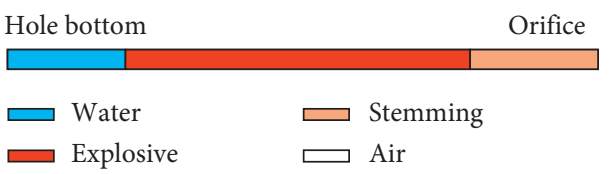

(d)

Figure 4: Charge structure. (a) Conventional charge. (b) Water interval charge at both ends. (c) Water interval charge at the orifice. (d) Water interval charge at the hole bottom.

of water interval charge at the bottom of hole is $3.19 \mathrm{~cm} \mathrm{~s}^{-1} \mathrm{~cm} / \mathrm{s}$.

The blasting vibration signal is an intuitive expression of the propagation of the blasting stress wave in the surrounding rock. Its peak value reflects the kinetic energy of the surrounding rock vibration, that is, the energy acting on the surrounding rock after detonation of the explosive. From the above, the energy utilisation of the explosives of the four charge structures can be preliminarily determined. When the water interval charge at both ends is used for construction, the water medium at the bottom of the hole acts like an explosive because of the incompressibility of water [25]. It can apply the most explosive energy to the surrounding rock, so its energy efficiency is highest among the four charge structures tested here. When the water interval charge at the hole bottom is used, as all of the water is at the 

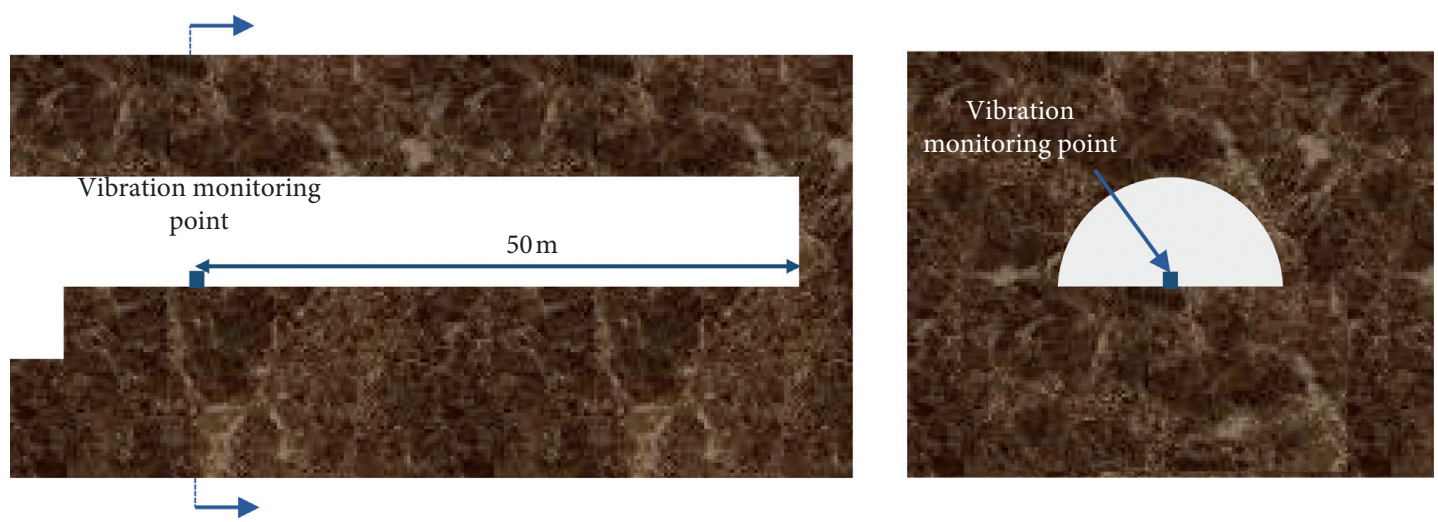

FIGURE 5: Layout of vibration monitoring points.

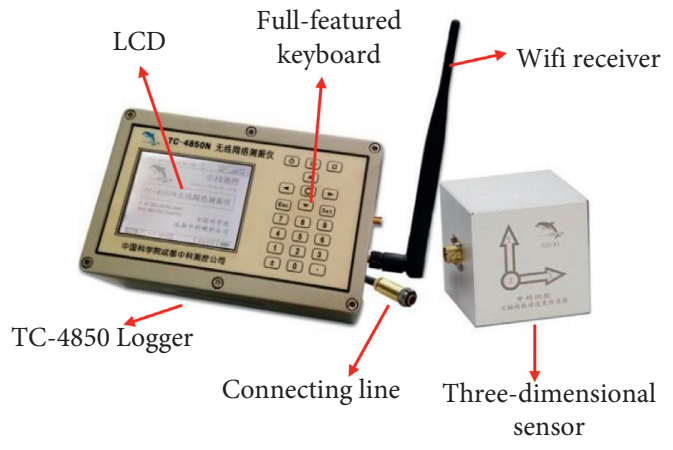

FIGURE 6: TC-4850 blasting signal recorder.

bottom of the hole, the stemming length of the hole is slightly shorter than that of the other three kinds of charges and explosive near the orifice, which easily leads to the loss of energy at the orifice after explosion and the minimum utilisation rate of explosive energy. The blasting energy utilisation rate of the water interval charge at the orifice is higher than that of the conventional charge structure. Its energy utilisation rate is between the water interval charge at both ends and the water interval charge at the hole bottom. The energy utilisation ratio of four charge structures is (in descending order) as follows: water interval charge at both ends, water interval charge at the orifice, conventional charge structure, and then the water interval charge at the hole bottom.

\section{Signal Analysis Based on HHT}

To analyse the blasting vibration signals more accurately, the HHT method is used to process the signals. HHT includes two parts: empirical mode decomposition (EMD) and the Hilbert transform. First, the signals are decomposed into multiple intrinsic mode functions (IMFs) by EMD, and then a Hilbert transform is applied to each IMF component thus generated. Finally, the energy distributions of IMF components, Hilbert energy spectrum, marginal spectrum, and instantaneous energy spectrum of the signals are obtained.

5.1. IMF Layer Energy Distribution Map. The energy distribution characteristics of blasting vibration signals reflect the relationship between the energy and frequency of blasting signals. Figure 8 shows the energy distribution of each IMF layer after HHT transformation of blasting vibration signals of four charge structures before and after noise reduction. The magnitude of the amplitude corresponds to the energy level of the IMF component. Each IMF component has a different amplitude and frequency: IMF $=1$ has the highest component frequency and relatively little energy, which represents the high-frequency noise in the blasting vibration signals and is the main object of noise reduction; $2 \leq \mathrm{IMF} \leq 5$ contains most of the energy of the signals and belongs to the dominant frequency band of the original signals; $6 \leq \mathrm{IMF} \leq 9$ contains less energy after signal decomposition, which is inherent to the signal itself. Comparing the IMF stratification energy before and after noise reduction, it can be seen that the wavelet threshold can effectively remove the noise at $\mathrm{IMF}=1$. The amplitude of IMF stratified energy before and after structural noise reduction is listed in Table 4.

After noise reduction, the maximum amplitude of the conventional charge structure is $1244.93 \mathrm{~cm}^{2} / \mathrm{s}^{2}$, the maximum amplitude of the water interval charge at both ends is $2733.52 \mathrm{~cm}^{2} / \mathrm{s}^{2}$, the maximum amplitude of the water interval charge at the orifice is $1560.04 \mathrm{~cm}^{2} / \mathrm{s}^{2}$, and the maximum amplitude of the water interval charge at the hole bottom is $1081.49 \mathrm{~cm}^{2} / \mathrm{s}^{2}$. The energy of the conventional charge structure, water interval charge at the orifice, and water interval charge at the hole bottom are mainly concentrated within IMF2 to IMF4, while that of the water interval charge at both ends is mainly concentrated within IMF2 to IMF5. Compared with the other three charge structures, the blasting vibration energy is also distributed in the low-frequency band when the water interval charge at both ends is adopted. It is necessary to pay attention to the influence on the structure to avoid resonance and the damage associated therewith.

5.2. Hilbert Energy Spectrum. Figure 9 shows Hilbert energy spectra of blasting vibration signals of the four charge structures: the more dense the points in the figure, the greater the energy. It can be seen that the fluctuations in energy of the blasting vibration signals generated by the four 


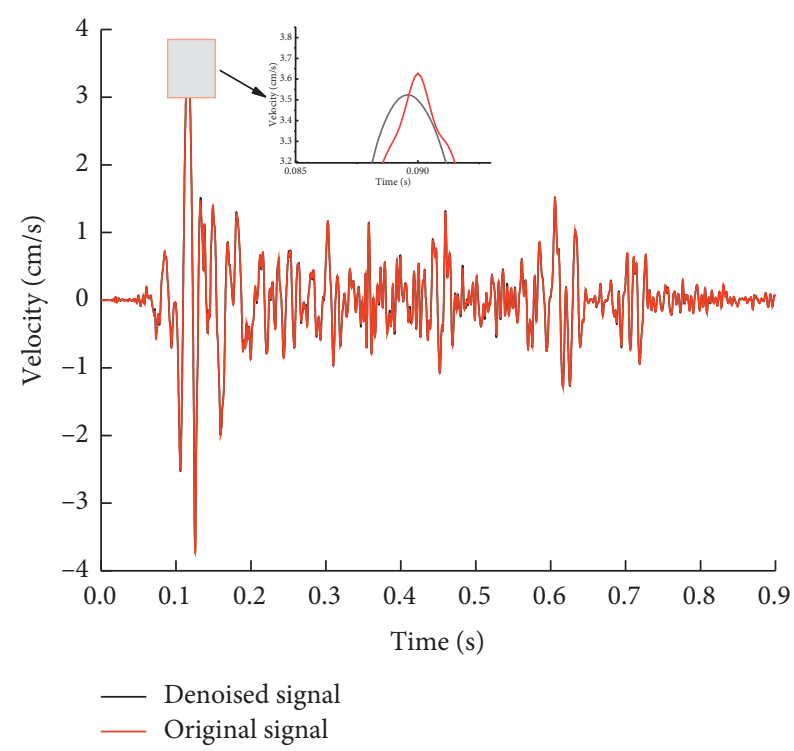

(a)

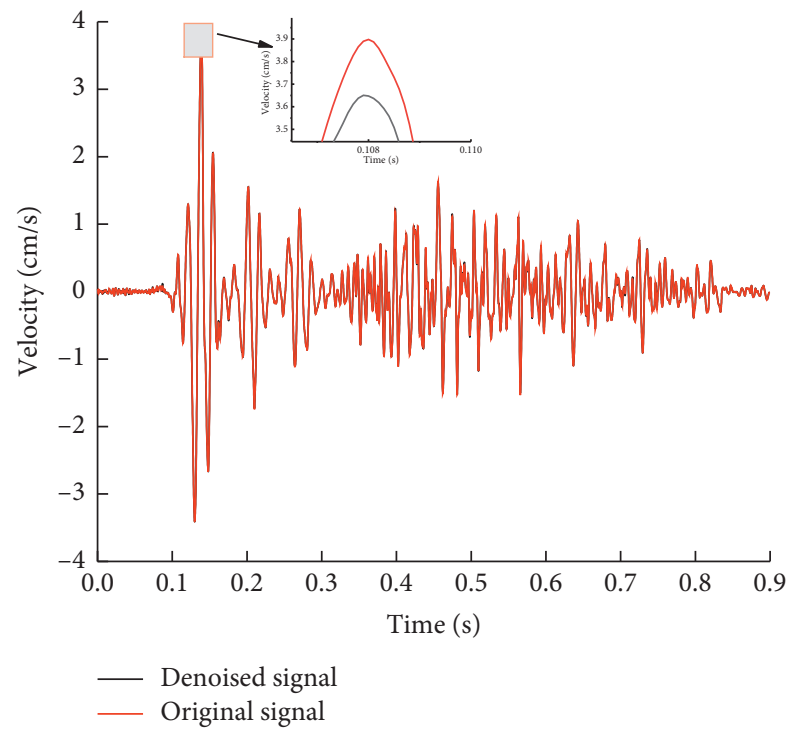

(c)

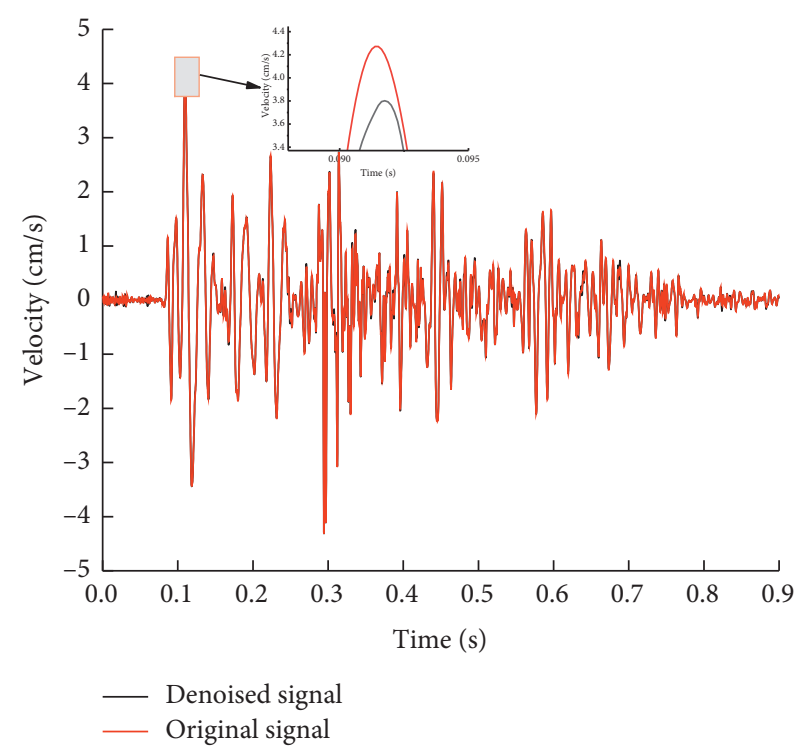

(b)

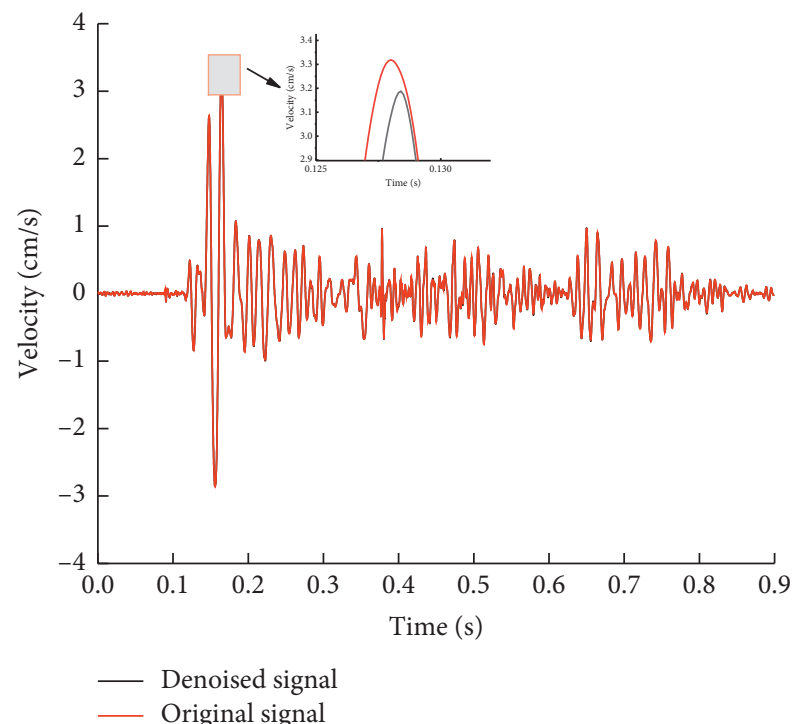

(d)

FIGURE 7: Comparison of original and denoised signals. (a) Conventional charge structure. (b) Water interval charge at both ends. (c) Water interval charge at the orifice. (d) Water interval charge at the hole bottom.

TABLE 3: Peak vibration velocity of different charge structures.

\begin{tabular}{lcc}
\hline Charge structure & Peak vibration velocity $\left(\mathrm{cm} \mathrm{s}^{-1}\right)$ & Surrounding rock grade \\
\hline Conventional charge structure & 3.52 & \\
Water interval charge at both ends & 4.14 & IV \\
Water interval charge at the orifice & 3.71 & 3.19 \\
Water interval charge at the hole bottom & & \\
\hline
\end{tabular}

charging structures are within $100 \mathrm{~Hz}$. By comparing the energy spectra of four types of charge structures, it can be seen that the frequency of blasting vibration signals of the water interval charge at both ends is uniformly distributed within the first $0.9 \mathrm{~s}$ and is below $100 \mathrm{~Hz}$. The frequency of the blasting vibration signals of the water interval charge at the orifice is less dense in the same area than that of the water interval charge structure at both ends but stronger than that of the conventional charge structure and water interval charge at the hole bottom. The frequency distributions of the blasting vibration signals of the conventional charge structure and water interval charge at the hole bottom are 


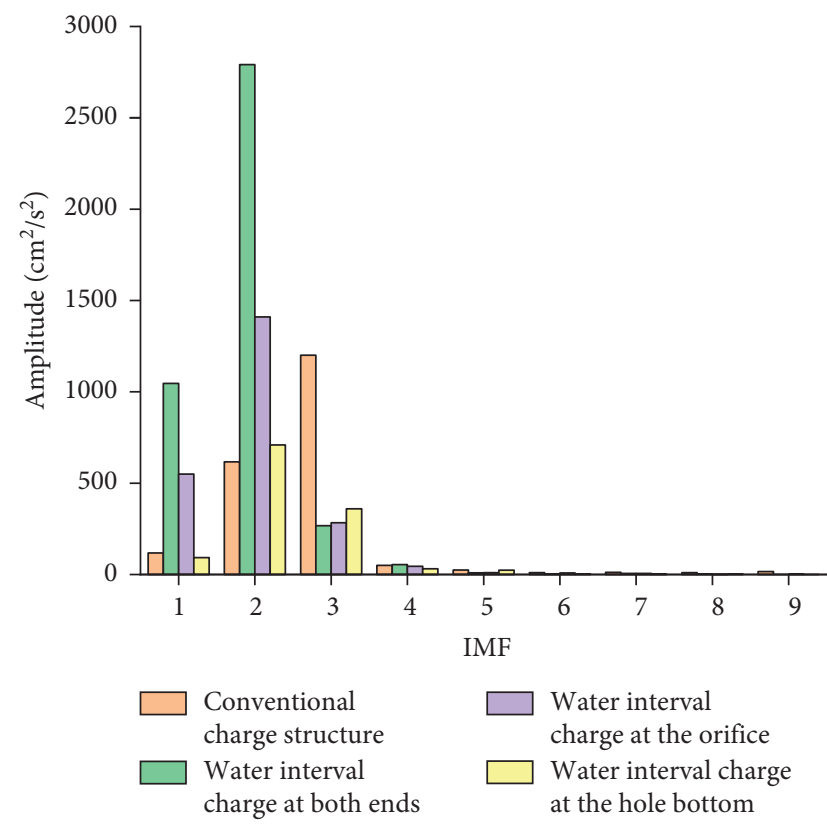

(a)

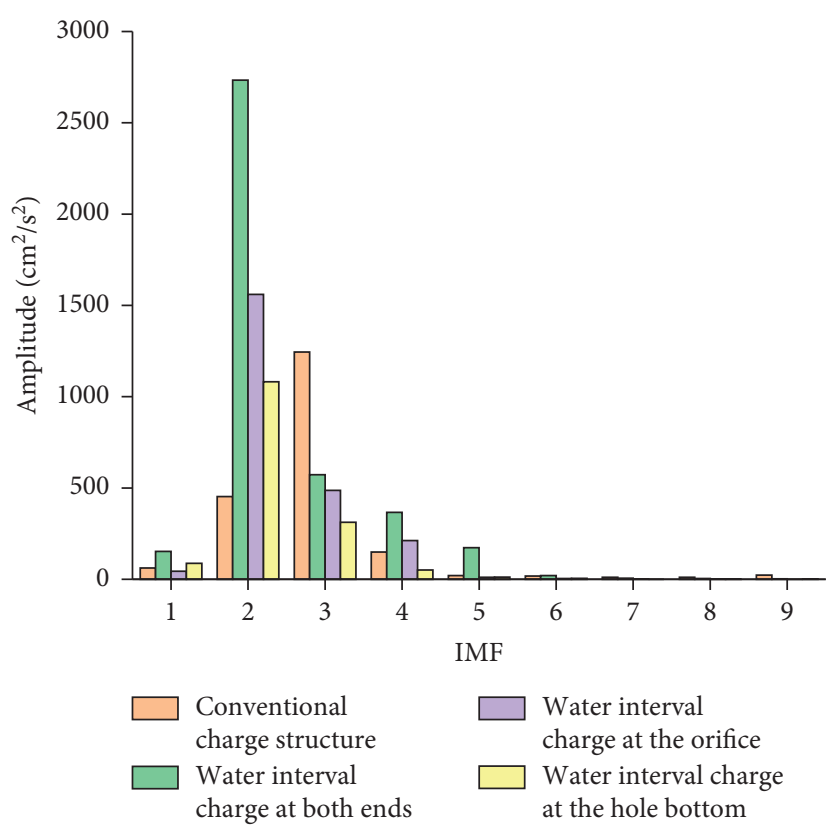

(b)

Figure 8: Energy distribution of the IMF layer. (a) Original signals. (b) Denoised signals.

TABle 4: Energy of each IMF layer before and after noise reduction for four charge structures.

\begin{tabular}{|c|c|c|c|c|c|c|c|c|}
\hline \multirow[b]{2}{*}{$\begin{array}{l}\text { IMF } \\
\text { component }\end{array}$} & \multicolumn{2}{|c|}{$\begin{array}{c}\text { Conventional charge } \\
\text { structure }\end{array}$} & \multicolumn{2}{|c|}{$\begin{array}{c}\text { Water interval charge at both } \\
\text { ends }\end{array}$} & \multicolumn{2}{|c|}{$\begin{array}{c}\text { Water interval charge at the } \\
\text { orifice }\end{array}$} & \multicolumn{2}{|c|}{$\begin{array}{l}\text { Water interval charge at } \\
\text { the hole bottom }\end{array}$} \\
\hline & $\begin{array}{c}\text { Original } \\
\text { signal } \\
\left(\mathrm{cm}^{2} / \mathrm{s}^{2}\right)\end{array}$ & $\begin{array}{l}\text { Denoised signal } \\
\left(\mathrm{cm}^{2} / \mathrm{s}^{2}\right)\end{array}$ & $\begin{array}{c}\text { Original } \\
\text { signal } \\
\left(\mathrm{cm}^{2} / \mathrm{s}^{2}\right)\end{array}$ & $\begin{array}{l}\text { Denoised signal } \\
\quad\left(\mathrm{cm}^{2} / \mathrm{s}^{2}\right)\end{array}$ & $\begin{array}{l}\text { Original signal } \\
\qquad\left(\mathrm{cm}^{2} / \mathrm{s}^{2}\right)\end{array}$ & $\begin{array}{l}\text { Denoised signal } \\
\left(\mathrm{cm}^{2} / \mathrm{s}^{2}\right)\end{array}$ & $\begin{array}{l}\text { Original signal } \\
\qquad\left(\mathrm{cm}^{2} / \mathrm{s}^{2}\right)\end{array}$ & $\begin{array}{c}\text { Denoised } \\
\text { signal } \\
\left(\mathrm{cm}^{2} / \mathrm{s}^{2}\right)\end{array}$ \\
\hline 1 & 117.55 & 61.74 & 1046.48 & 152.46 & 549.43 & 44.20 & 101.6183 & 87.79 \\
\hline 2 & 616.57 & 453.23 & 2791.32 & 2733.52 & 1410.10 & 1560.04 & 709.31983 & 1081.49 \\
\hline 3 & 1200.64 & 1244.93 & 266.96 & 572.90 & 283.00 & 487.04 & 359.94249 & 312.52 \\
\hline 4 & 49.73 & 149.61 & 54.62 & 366.70 & 44.94 & 212.24 & 31.25765 & 50.60 \\
\hline 5 & 24.64 & 20.68 & 9.27 & 173.26 & 10.52 & 11.07 & 23.62858 & 11.98 \\
\hline 6 & 10.37 & 17.79 & 1.68 & 19.99 & 8.52 & 4.07 & 3.12566 & 4.95 \\
\hline 7 & 11.53 & 10.74 & 5.65 & 5.88 & 5.92 & 1.69 & 1.99501 & 0.41 \\
\hline 8 & 10.42 & 10.97 & 3.08 & 4.60 & 1.13 & 1.25 & 2.81837 & 0.99 \\
\hline 9 & 16.40 & 22.90 & 0.06 & 2.88 & 1.77 & 0.14 & 0.32634 & 1.36 \\
\hline
\end{tabular}

the worst in the above range, and a sparse area appears therein. By analysing the Hilbert energy spectrum, it can be explained that the explosive energy can be fully utilised when a water interval charge at both ends is used. The energy utilisation rate of a water interval charge at the orifice is slightly lower than that of a water interval charge at both ends, and use of a conventional charge structure or water interval charge at the hole bottom leads to a loss of explosive energy.

5.3. Hilbert Marginal Spectrum. The marginal spectrum can be obtained by integrating the corresponding amplitude of the frequency over the whole time period. It is the sum of the amplitudes of the frequency in time, reflecting the total energy and energy concentration of frequency in the whole process of time. It can be seen from Figure 10 that the energy of the four charge structures is mainly concentrated in the range of $0 \mathrm{~Hz}$ to $100 \mathrm{~Hz}$, and the energy gradually decreases as the frequency increases, which is consistent with the conclusion reached when analysing the energy spectra; however, compared with the other three charging structures, the vibration signal energy of the water interval charged at both ends is not only concentrated in the range of $20 \mathrm{~Hz}$ to $70 \mathrm{~Hz}$ but is also concentrated in the low-frequency range $(6 \mathrm{~Hz}$ to $11 \mathrm{~Hz})$, corresponding to IMF5 in the energy distribution of the IMF. Because the natural frequency of the general buildings is from $3 \mathrm{~Hz}$ to $9 \mathrm{~Hz}$, when using the water interval charge at both ends for blasting, it is necessary to increase the main vibration frequency of the original vibration signals by reducing the amount of charge in the single section charge and adopt frequency shift technology $[26,27]$ to avoid the natural frequency of the structure and reduce resonance-induced damage thereof. 


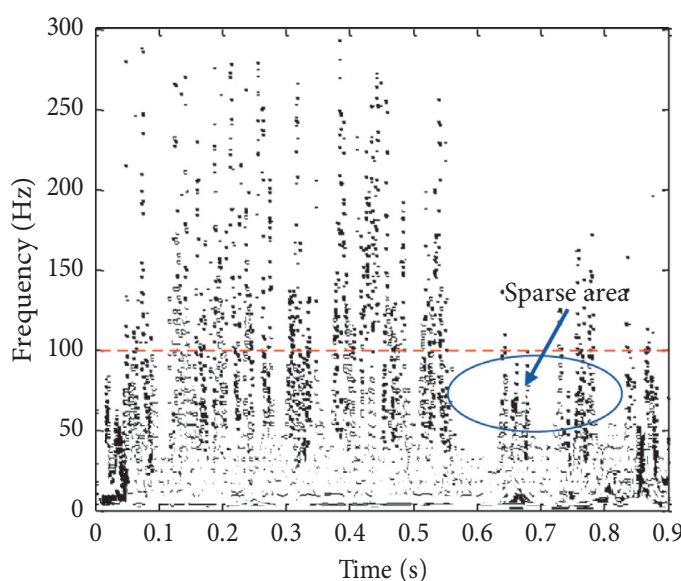

(a)

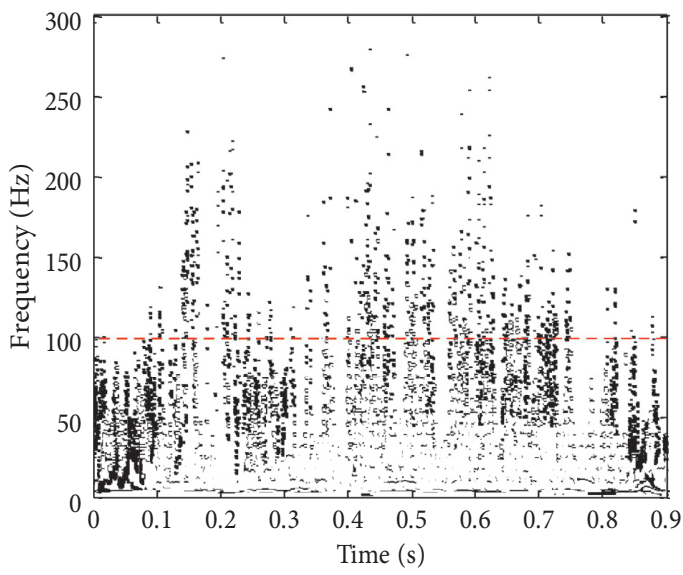

(c)

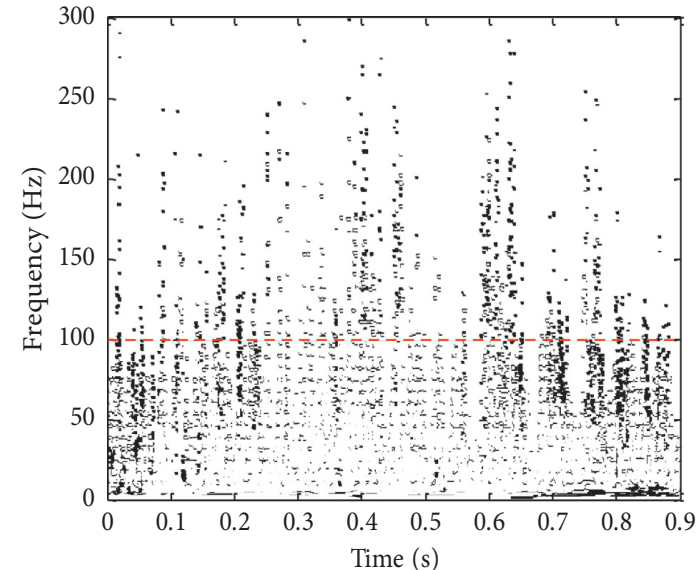

(b)

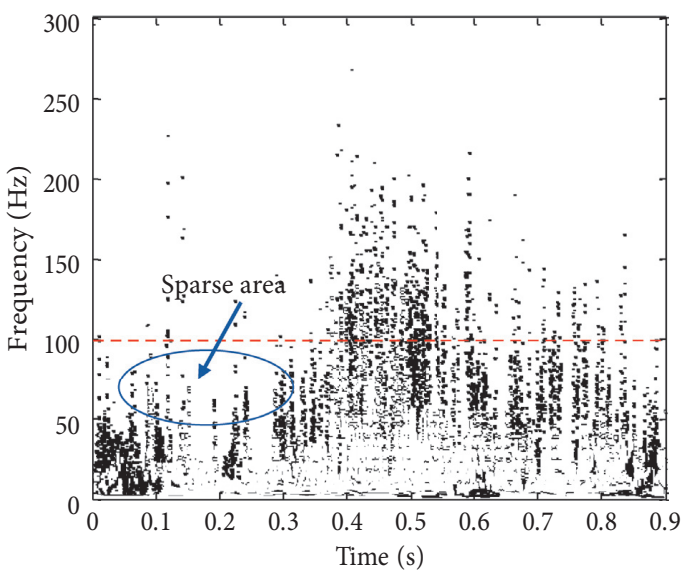

(d)

Figure 9: Hilbert energy spectra. (a) Conventional charge structure. (b) Water interval charge at both ends. (c) Water interval charge at the orifice. (d) Water interval charge at the hole bottom.

5.4. Instantaneous Energy Distribution Map. Instantaneous energy is the accumulation of blasting vibration energy over the whole time period and reflects the changes therein. Figure 11 shows a comparison between the vibration signals and the instantaneous energy spectrum after denoising the signals from the four charge structures. It can be seen that the instantaneous energy is consistent with the blasting vibration signals. When the vibration signals change abruptly, the instantaneous energy also changes abruptly and reaches its peak value. We compare the instantaneous peak energies of each explosive charge configuration and the total energy in each section of the four charge structures after detonation (Table 5). Because there is almost no instantaneous energy after the explosion of the 15 segment explosive, it is not counted.

It can be seen from Table 5 that, after the explosion of each segment of the blast-hole, the instantaneous total energy is (in descending order) as follows: the water interval charge at both ends, the water interval charge at the orifice, the conventional charging structure, and the water interval charge at the hole bottom. The corresponding maximum instantaneous total energy is $50.94 \mathrm{~cm}^{2} \mathrm{~Hz} / \mathrm{s}^{2}, 22.8 \mathrm{~cm}^{2} \mathrm{~Hz} / \mathrm{s}^{2}, 18.46 \mathrm{~cm}^{2} \mathrm{~Hz} / \mathrm{s}^{2}$, and $11.61 \mathrm{~cm}^{2} \mathrm{~Hz} / \mathrm{s}^{2}$, respectively. This shows that, for a given amount of charge, the water interval charge at both ends can better transfer the explosive energy to the surrounding rock for breaking, which is consistent with the conclusion arising from our analysis of the energy spectra of the blasting vibration signals of the four charge structures.

\section{Engineering Application}

6.1. Blasting Effect. The blasting effects of the four charging structures are, respectively, calculated. The statistical contents include unit explosive consumption, blast-holes utilisation rate, and rock fragmentation. The results are shown in Table 6.

It can be seen that, with the same blasting volume, the water interval charge at both ends is superior to the other three charge structures in terms of unit explosive consumption, blast-holes utilisation rate, and rock fragmentation. 


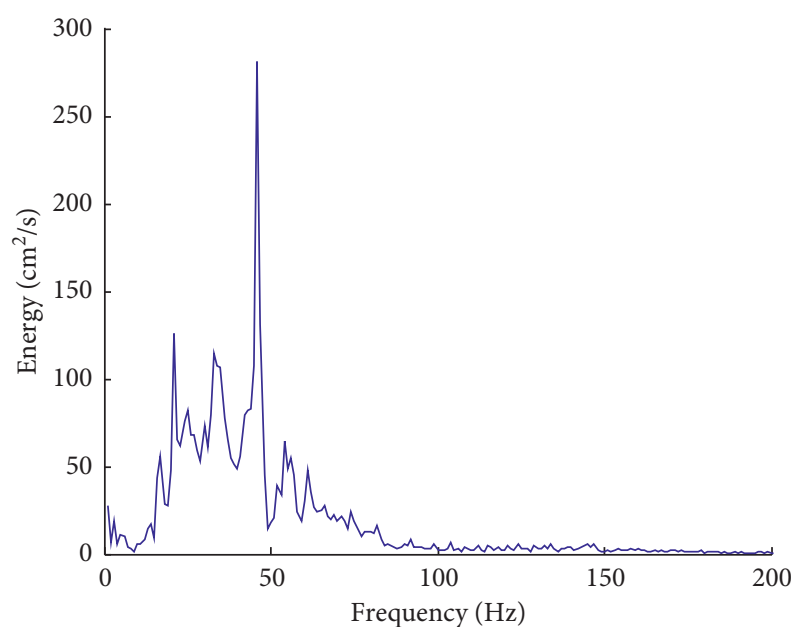

(a)

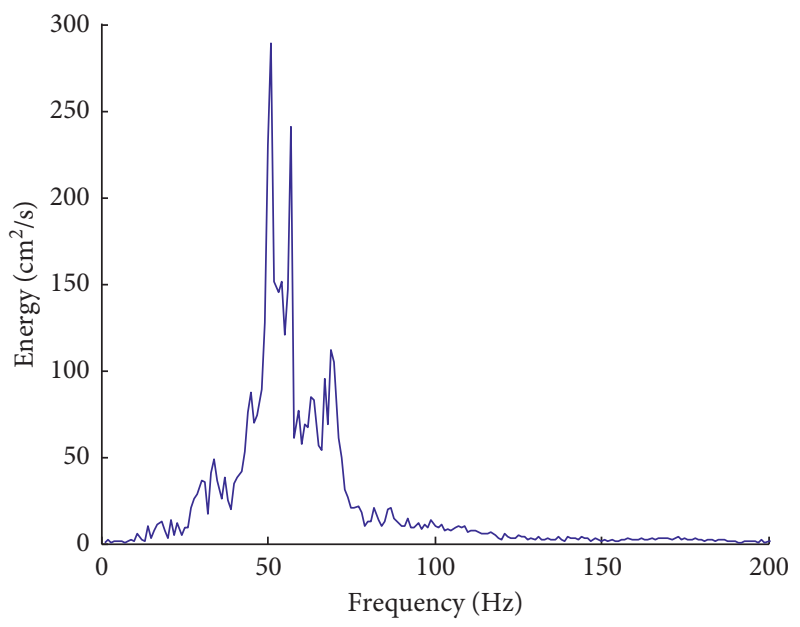

(c)

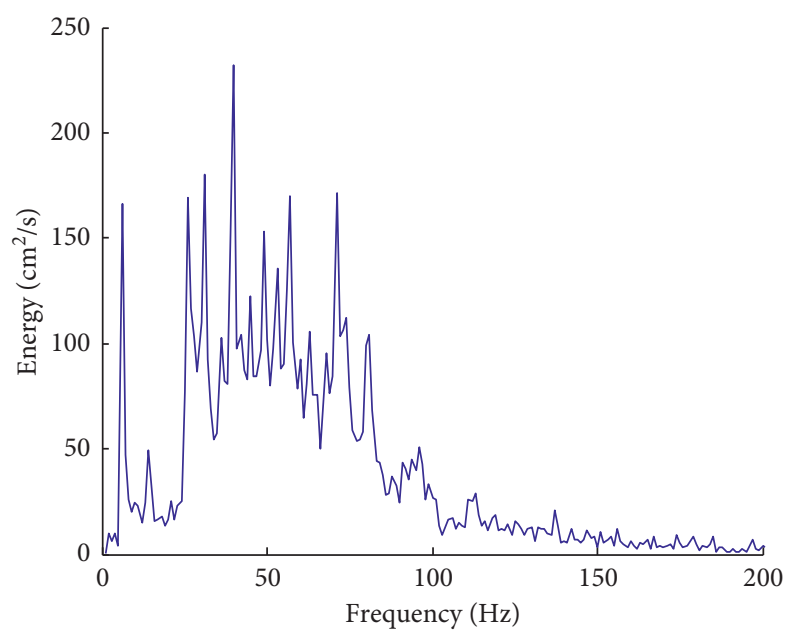

(b)

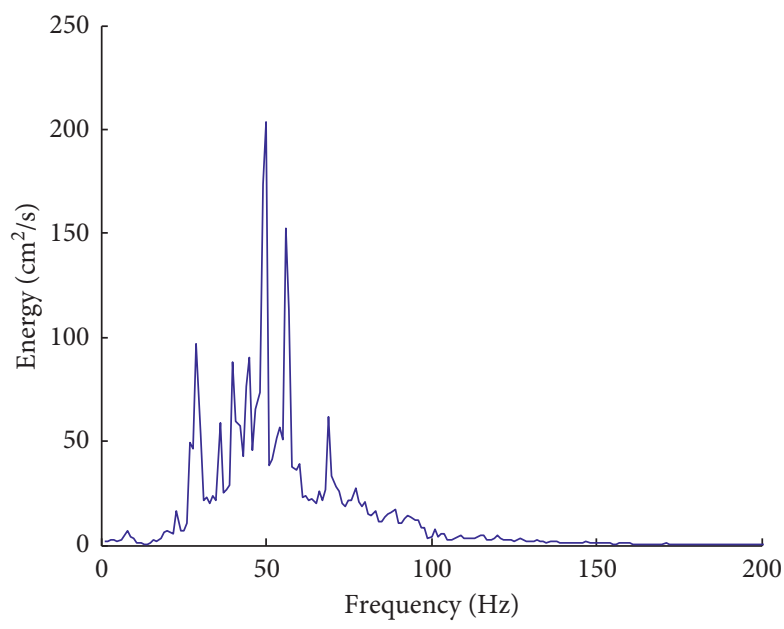

(d)

FIgURE 10: Signal marginal spectra. (a) Conventional charge structure. (b) Water interval charge at both ends. (c) Water interval charge at the orifice. (d) Water interval charge at the hole bottom.

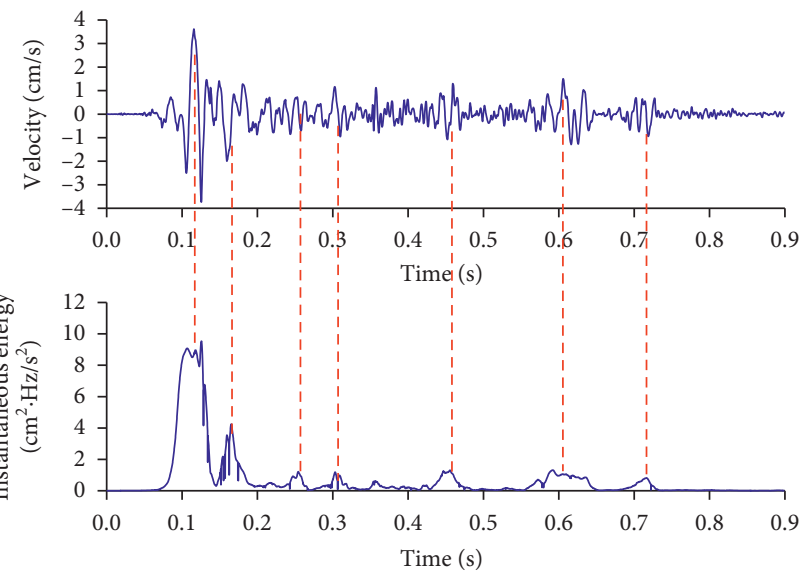

(a)

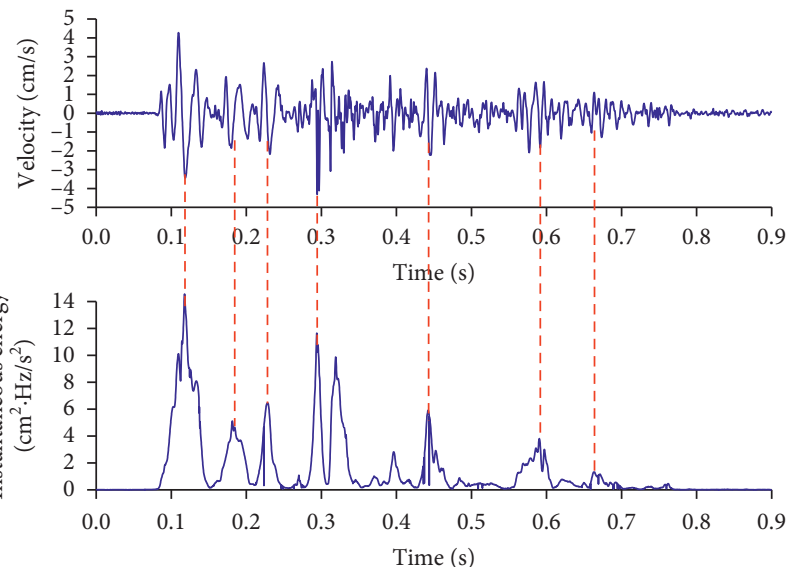

(b)

FIgURE 11: Continued. 


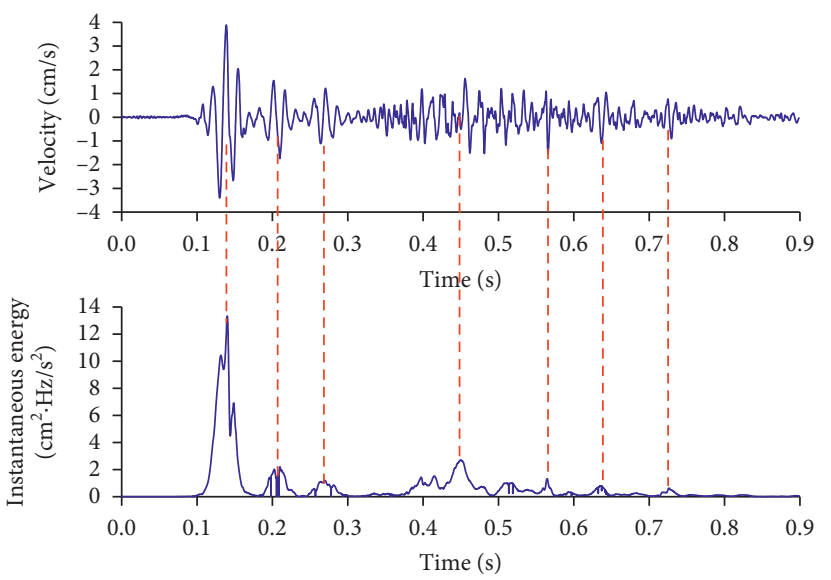

(c)

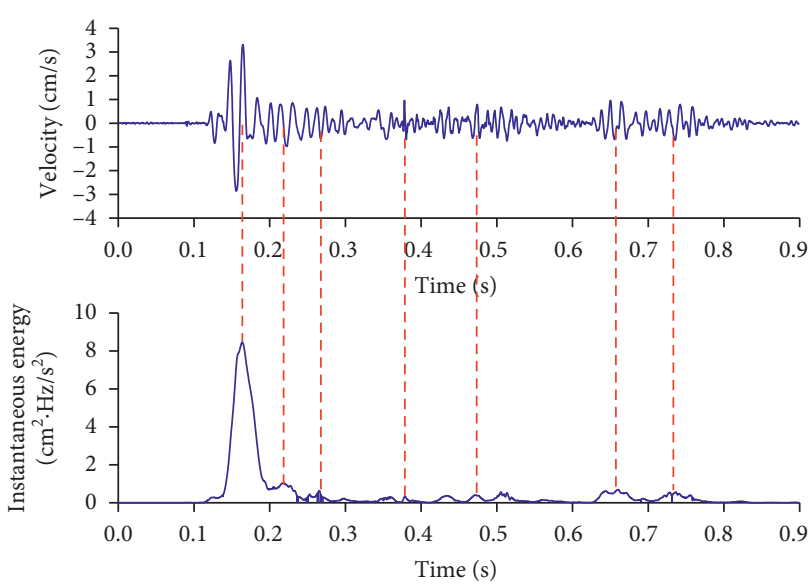

(d)

FIGURE 11: Comparison of instantaneous energy and waveforms. (a) Conventional charge structure. (b) Water interval charge at both ends. (c) Water interval charge at the orifice. (d) Water interval charge at the hole bottom.

TABLE 5: Instantaneous peak energies of the four charge structures.

\begin{tabular}{|c|c|c|c|c|}
\hline $\begin{array}{l}\text { Detonator } \\
\text { section }\end{array}$ & $\begin{array}{l}\text { Conventional charge } \\
\text { structure }\left(\mathrm{cm}^{2} \cdot \mathrm{Hz} / \mathrm{s}^{2}\right)\end{array}$ & $\begin{array}{l}\text { Water interval charge at both } \\
\text { ends }\left(\mathrm{cm}^{2} \cdot \mathrm{Hz} / \mathrm{s}^{2}\right)\end{array}$ & $\begin{array}{l}\text { Water interval charge at the } \\
\text { orifice }\left(\mathrm{cm}^{2} \cdot \mathrm{Hz} / \mathrm{s}^{2}\right)\end{array}$ & $\begin{array}{l}\text { Water interval charge at the hole } \\
\text { bottom }\left(\mathrm{cm}^{2} \cdot \mathrm{Hz} / \mathrm{s}^{2}\right)\end{array}$ \\
\hline 1 & 10.85 & 13.97 & 13.18 & 8.39 \\
\hline 3 & 2.76 & 5.31 & 2.11 & 1.13 \\
\hline 5 & 0.85 & 6.50 & 1.32 & 0.38 \\
\hline 7 & 0.90 & 9.32 & 1.45 & 0.43 \\
\hline 9 & 0.68 & 7.22 & 2.69 & 0.38 \\
\hline 11 & 1.13 & 2.44 & 1.19 & 0.47 \\
\hline 13 & 1.29 & 6.18 & 0.86 & 0.43 \\
\hline $\begin{array}{l}\text { Total } \\
\text { energy }\end{array}$ & 18.46 & 50.94 & 22.8 & 11.61 \\
\hline
\end{tabular}

TABLE 6: Blasting effect of the four charging structures.

\begin{tabular}{lcccc}
\hline Charge structure & $\begin{array}{c}\text { Blasting } \\
\text { volume }\left(\mathrm{m}^{3}\right)\end{array}$ & $\begin{array}{c}\text { Unit explosive } \\
\text { consumption }\left(\mathrm{kg} / \mathrm{m}^{3}\right)\end{array}$ & $\begin{array}{c}\text { Blast-holes } \\
\text { utilisation rate }(\%)\end{array}$ & $\begin{array}{c}\text { Rock } \\
\text { fragmentation }(\mathrm{cm})\end{array}$ \\
\hline Conventional charge structure & 237 & 0.91 & $89 \%$ & 30 \\
Water interval charge at the orifice & 237 & 0.83 & $93 \%$ & 36 \\
Water interval charge at both ends & 237 & 0.81 & $95 \%$ & 25 \\
Water interval charge at the hole bottom & 237 & 0.86 & $90 \%$ & 30 \\
\hline
\end{tabular}

TABLE 7: Dust suppression effect of the four charge structures.

\begin{tabular}{lcccc}
\hline Charge structure & $\begin{array}{c}\text { Filter membrane quality } \\
\text { before sampling }(\mathrm{g})\end{array}$ & $\begin{array}{c}\text { Filter membrane quality } \\
\text { after sampling }(\mathrm{g})\end{array}$ & $\begin{array}{c}\text { Difference }(\mathrm{g}) \\
\text { concentration }\left(\mathrm{mg} / \mathrm{m}^{3}\right)\end{array}$ \\
\hline Conventional charge structure & 1.994 & 2.184 & 0.190 & 158.75 \\
Water interval charge at the hole bottom & 1.922 & 2.091 & 0.169 & 140.83 \\
Water interval charge at the orifice & 1.903 & 2.062 & 0.159 & 132.50 \\
Water interval charge at both ends & 1.990 & 2.151 & 0.161 & 134.17 \\
\hline
\end{tabular}

6.2. Dust Suppression Effect. In the construction process, the dust concentration of the four charging structures after blasting is monitored by the method of filter membrane weighing. In order to ensure the accuracy of monitoring, the ventilation shall be suspended after blasting, and the dust collector shall be turned on. The acquisition parameter is $120 \mathrm{~L} / \mathrm{min}$, and the acquisition time is $10 \mathrm{~min}$. See Table 7 for the results. 
Compared with the above four charge structures, the dust concentration of conventional charging structure is $158.75 \mathrm{mg} / \mathrm{m}^{3}$, which is the highest among the four charge structures, indicating that water seal blasting can reduce the blasting dust. The dust concentration of the water interval charge at the hole bottom is $140.83 \mathrm{mg} / \mathrm{m}^{3}$, which is the highest in the water-sealed charge structure. The dust concentration of the water interval charge at both ends after blasting is slightly higher than that of the water interval charge at the orifice, but the difference is only $1.67 \mathrm{mg} / \mathrm{m}^{3}$. Combined with the results obtained in the first half of the paper, the water interval charge at both ends has the advantages of reducing unit explosive consumption, improving blast-holes utilisation rate and rock fragmentation, so the advantages of using the water interval charge at both ends are significant.

\section{Conclusion}

(1) The wavelet threshold method can effectively eliminate high-frequency noise in the blasting vibration signals and retain information carried by the vibration signal itself. The frequency and energy of the blasting vibration signals of the water interval charge at both ends are densely distributed in the range of $0 \mathrm{~s}$ to $0.9 \mathrm{~s}$ and below $100 \mathrm{~Hz}$. The frequency and energy of the blasting signals of the other three charging structures are reduced within the same range, sparse areas appear, and the instantaneous total energy is smaller than that with a water interval charge at both ends, which shows that the water interval charge at both ends can effectively apply explosive energy to the surrounding rock and reduce energy loss in the explosive.

(2) The blasting vibration signal energy of the water interval charge at both ends is mainly concentrated in components IMF2 to IMF5, and the corresponding frequencies are concentrated at $6 \mathrm{~Hz}$ to $11 \mathrm{~Hz}$ and $20 \mathrm{~Hz}$ to $70 \mathrm{~Hz}$, while the blasting vibration signal energy of three other charge structures is mainly distributed in components IMF2 to IMF4, corresponding frequencies are concentrated within $20 \mathrm{~Hz}$ to $70 \mathrm{~Hz}$, and the distribution at low frequencies is not obvious.

(3) It is the best way to use the water interval charge at both ends for tunnel excavation blasting, but it is necessary to increase the main vibration frequency of the original vibration signals by reducing the single section charge and using frequency shift technology to avoid the natural frequency of the structure and reduce resonanceinduced damage.

\section{Data Availability}

The data used to support the findings of this study are included within the article.

\section{Conflicts of Interest}

The authors declare that there are no conflicts of interest regarding the publication of this paper.

\section{Acknowledgments}

This work was supported by the National Natural Science Foundation of China (51778025 and 51678018).

\section{References}

[1] H. L. Fei, M. Liu, G. J. Qu, and Y. Gao, "A method for blasting vibration signal denoising based on ensemble empirical mode decomposition-wavelet threshold," Explosion and Shock Waves, vol. 38, no. 1, pp. 112-118, 2018.

[2] H. P. Yuan, X. L. Liu, Y. Liu et al., "Analysis of acoustic wave frequency spectrum characters of rock mass under blasting damage based on the HHT method," Advances in Civil Engineering, vol. 2018, Article ID 9207476, 8 pages, 2018.

[3] H. Y. Yu and S. J. Yu, "Study on forecasting intensity of ground motion induced by engineering explosion," Earthquake Engineering and Engineering Vibration, vol. 24, no. 1, pp. 122-129, 2004.

[4] D. Huang, S. Cui, and X. Li, "Wavelet packet analysis of blasting vibration signal of mountain tunnel," Soil Dynamics and Earthquake Engineering, vol. 117, pp. 72-80, 2019.

[5] Q. Liang, Y. An, L. Zhao, D. Li, and L. Yan, "Comparative study on calculation methods of blasting vibration velocity," Rock Mechanics and Rock Engineering, vol. 44, no. 1, pp. 93-101, 2011.

[6] S.-h. Chen, S.-w. Hu, Z.-h. Zhang, and J. Wu, "Propagation characteristics of vibration waves induced in surrounding rock by tunneling blasting," Journal of Mountain Science, vol. 14, no. 12, pp. 2620-2630, 2017.

[7] D. W. Liu, S. U. Chuang, and G. Y. Gao, "New method for blasting hazards evaluation based on wavelet analysis of blasting vibration signals," Journal of Central South University (Science and Technology), vol. 41, no. 4, pp. 1574-1577, 2010.

[8] X. L. Cao, W. X. Gao, and H. Tao, "Analysis of blasting vibration signal by HHT transform," Acta Armamentarii, vol. 37, no. S2, pp. 107-113, 2016.

[9] P. Wang and H. L. Meng, "Analysis of adjacent existing tunnel blasting vibration signal based on HHT method," Engineering Blasting, vol. 24, no. 6, pp. 70-74, 2018.

[10] R. F. Ning and S. P. Zhang, "Application of wavelet packet analysis in blasting vibration signal energy attenuation law," Blasting, vol. 31, no. 1, pp. 1-4+37, 2014.

[11] Z. Li, R. H. Ma, W. C. Wang et al., "Multifractal based on wavelets and its application to processingblasting vibration signal of rock," Journal of PLA University of Science and Technology (Natural Science), vol. 6, no. 2, pp. 158-161, 2005.

[12] R. S. Yang, X. Q. Fu, S. P. Zhang et al., "Analysis of blasting vibration signal based on EEMD fractal and quadratic timefrequency SPWV distribution," Journal of Vibration and Shock, vol. 35, no. 22, pp. 41-47, 2016.

[13] R. S. Yang, X. Q. Fu, G. L. Yang et al., "Application of EMD and FSWT combination method in blasting vibration signal analysis," Journal of Vibration \& Shock, vol. 36, no. 2, pp. 58-64, 2017.

[14] D. H. Shao, "Denoising of tunnel blasting vibration signal based on CEEMD low pass," Engineering Blasting, vol. 23, no. 6, pp. 5-10, 2017. 
[15] X. L. Wei, R. L. Lin, S. Y. Liu et al., "A de-noising method for chaotic signals based on improved EEMD," Journal of $V i$ bration and Shock, vol. 36, no. 17, pp. 35-41, 2017.

[16] Y. Z. Rao, L. Wang, R. Rao et al., "A method for blasting vibration signal denoising based on empircal mode decomposition and wavelet threshold," Journal of Fuzhou University (Natural Science Edition), vol. 43, no. 2, pp. 271-277, 2015.

[17] D. L. Donoho and I. M. Johnstone, "Ideal spatial adaptation by wavelet shrinkage," Biometrika, vol. 81, no. 3, pp. 425-455, 1994.

[18] W. J. Su and Y. Zhou, "Wavelet transform threshold noise reduction methods and the application in engineering," Microcomputer Information, vol. 24, no. 1, pp. 281-283, 2008.

[19] F. Z. Zhang, H. Wei, and B. W. Tan, "An improved wavelet threshold denoising method," Study on Optical Communications, vol. 2, no. 206, pp. 75-78, 2018.

[20] H. Xu, J. C. Liu, X. Gao et al., "Selection of denoising method for vibration signal of roof blasting in Wushan Copper Mine," Mining Technology, vol. 17, no. 2, pp. 93-95+104.

[21] N. E. Huang, Z. Shen, S. R. Long et al., "The empirical mode decomposition and the Hilbert spectrum for nonlinear and non-stationary time series analysis," Proceedings of the Royal Society of London. Series A: Mathematical, Physical and Engineering Sciences, vol. 454, no. 1971, pp. 903-995, 1998.

[22] State Administration of Work Safety, Blasting safety regulations GB 6722-2014, China Standards Press, Beijing, China, 2015.

[23] G. Chao and S. Zhou, "Wavelet transform threshold noise reduction methods in the oil pipeline leakage monitoring and positioning system," Journal of Electronics, vol. 27, no. 3, pp. 405-411, 2010.

[24] L. Han, D. S. Liu, C. W. Xin et al., "Trend removing methods of vibration signals of deep hole bench blasting in near field," Explosion and Shock Waves, vol. 38, no. 5, pp. 1006-1012, 2018.

[25] G. Y. He, Energy Saving and Environmental Protection Engineering Blasting, China Railway Publishing House, Shanxi, China, 2007.

[26] H. H. Yan, X. L. Zhao, X. J. Li et al., "Under the shallow buried tunnel in both the build of short-delay blasting vibration method," Journal of Underground Space and Engineering, vol. 11, no. 5, pp. 1328-1332, 2015.

[27] H. C. Li, L. F. Luan, Z. Y. Zhang et al., "Test research on optimizing blasting parameters in Baideng phosphprus mine," Engineering Blasting, vol. 17, no. 3, pp. 41-43, 2011. 